Running head: READING COMPREHENSION IN BILINGUAL READERS OF ENGLISH

The Simple View of Reading Made Complex by Morphological Decoding Fluency in Bilingual

Fourth-Grade Readers of English

Dongbo Zhang

University of Exeter, Exeter, Devon, United Kingdom

Sihui Ke

University of Kentucky, Lexington, Kentucky, USA 


\begin{abstract}
This study examined the complexity of the Simple View of Reading focusing on morphological decoding fluency in fourth-grade readers of English in Singapore. The participants were three groups of students who all learned to become bilingual and biliterate in the English language (EL) and their respective ethnic language in school but differed in the home language they used. The first group was ethnic Chinese students who used English as the dominant home language (Chinese EL1); the other two groups were ethnic Chinese and Malay students whose dominant home language was not English but Chinese (Chinese EL2) and Malay (Malay EL2), respectively. The measures included pseudo word decoding (phonemic decoding), timed decoding of derivational words (morphological decoding fluency), oral vocabulary, and passage comprehension. Path analysis showed that oral vocabulary significantly predicted reading comprehension across all three groups; yet a significant effect of morphological decoding fluency surfaced in the Chinese EL1 and Malay EL2 groups but not the Chinese EL2 group. Multi-group path analysis and commonality analysis further confirmed that morphological decoding played a larger role in the in the Chinese EL1 and Malay EL2 groups. These findings are discussed in light of the joint influence of target language experience and cross-linguistic influence on second language or bilingual reading development.
\end{abstract}




\section{The Simple View of Reading Made Complex by Morphological Decoding Fluency in}

\section{Bilingual Fourth-Grade Readers of English}

Reading comprehension requires the orchestration of a set of component skills and strategies where substantial individual differences often exist (Cain \& Barnes, 2017; Perfetti, 1999). An early conceptualization of this issue is the Simple View of Reading (SVR), which contends that reading comprehension ( $\mathrm{RC}$ ) is essentially a product of two factors, that is, decoding (D) and listening comprehension (LC) (RC = D X LC; Gough \& Tunmer, 1986). ${ }^{1}$

Since it was first outlined by Gough and Tunmer, the SVR has caught a lot of research attention; many findings have been generated that show the SVR is simple (i.e., underlying processes of reading comprehension explained by only two factors) yet complex (e.g., details of each factor and the interplay of the two factors in diverse groups of readers) (Kirby \& Savage, 2008).

There are, nonetheless, a number of issues that still await to be further addressed. For example, does the SVR have a place for morphological decoding (i.e., decoding based on morphemes or a larger psycholinguistic grain size unit; Ziegler \& Goswami, 2005), over and beyond phonological decoding (i.e., decoding based on letter-sound correspondences), in English reading acquisition? Additionally, can the SVR accommodate the complexity of second language (L2) or bilingual reading acquisition where, compared to monolingual (first language / L1) reading acquisition, readers are less exposed to the target language and where cross-linguistic 
influence is naturally expected (Koda, 2008)? Overall, questions remain to be answered as to how morphological decoding may play a role in the SVR in L2 readers as compared to L1 readers on the one hand, and in L2 readers with disparate L1 backgrounds on the other.

This study sets out to address the above questions and reexamine the SVR to reveal its complexity in young bilingual readers of English with a focus on morphological decoding fluency. The study was conducted in Singapore, a multilingual country where English is both the medium of instruction and a school subject and where students of different ethnicities also learn as another school subject their respective ethnic language (e.g., Malay or Chinese), which is locally called Mother Tongue (MT) but not necessarily a student's first language (Dixon, 2005). ${ }^{2}$ The participants were three groups of Grade 4 readers of English who differed in their dominant home language. The contributions of different decoding measures, particularly morphological decoding fluency, and oral vocabulary to reading comprehension were examined for each group and then compared across groups through multi-group path analysis and commonality analysis.

The findings enrich the current theorizations on decoding in reading comprehension in light of the SVR, particularly in bilingual or non-native readers of English. It highlights a developmentally important role of morphological decoding as well as the joint influence of target language experience and L1 background/processing experience on L2 reading development. Pedagogically, they shed light on how English literacy instruction could and should 
accommodate the differential needs of bilingual readers of English, who often come from

culturally and linguistically diverse backgrounds (August \& Shanahan, 2006). Although the study was conducted in Singapore, the implications of the findings are far wider and pertain to any place of the world where students from diverse home language backgrounds are taught to become literate in English in the same classrooms/school setting (García, 2008).

\section{The Simple View of Reading is Simple Yet Complex}

The SVR has been widely known as a general framework that outlines the broad landscape of reading comprehension in light of two component processes: decoding and listening comprehension. Theoretically, one needs to recognize words in a written text and then integrate word meanings and draw upon oral language or listening comprehension processes, such as sentence and discourse processing and background knowledge, for comprehending that text.

Both components are considered to be essential and neither is sufficient by itself.

Since it was first put forth by Gough and Tunmer (1986), a number of questions have been asked of and models tested on the SVR, which overall has been recognized as simple yet complex. It is simple in that the underlying processes of reading comprehension are encapsulated in only two components. It is complex in that many questions remain to be answered on details of the framework (Kirby \& Savage, 2008). For example, what skills does each component specifically entail (García \& Cain, 2014; LARRC, 2017); how do the two components interplay 
in reading comprehension (e.g., additive and/or multiplicative) (Chen \& Vellutino, 1997; Joshi \& Aaron, 2000); is there anything important missing (Johnston \& Kirby, 2006)?

In answering these questions, special attention has been given to the decoding component (García \& Cain, 2014). When Gough and Tunmer (1986) first outlined the SVR, decoding seemed to be primarily discussed in light of readers relying on grapheme-phoneme correspondences (i.e., phonemic decoding); and many studies subsequently considered decoding of pseudo words in this respect (e.g., Johnston \& Kirby, 2006; Savage, 2006). Yet, in line with the dual route of reading (Coltheart, 2005), reading in an alphabetic language, particularly English, involves both a phonological route and a route of sight word recognition (i.e., recognition without inducing phonological processes). Johnston and Kirby (2006) found reading comprehension was a function of the product of listening comprehension with both pseudo word decoding and sight word recognition in third-grade English-speaking students.

Another question concerning the decoding component is legitimacy of decoding fluency, that is, rapid decoding with accuracy rather than basic accuracy without a speed consideration (García \& Cain, 2014; Kirby \& Savage, 2008). In other words, is decoding (accuracy) alone, together with language comprehension, sufficient to explain reading comprehension? Gough and Tunmer (1986) discussed the decoding component in light of quick and accurate recognition of words; yet, most subsequent studies focused only on phonemic decoding accuracy. Phonology 
and its mapping to print is a closed system in alphabetic languages; developmentally, basic decoding accuracy based on letter-sound correspondences is asymptotic in English (Paris, 2005). Overall, findings from English-speaking readers suggested that (phonemic) decoding fluency has a legitimate role in the SVR; and developmentally its role is more important than basic accuracy (Silverman, Speece, Harring, \& Ritchey, 2013; Tilstra, McMaster, Van den Broek, Kendeou, \& Rapp, 2009; see Adlof, Catts, \& Little, 2006, however, for a different finding). Fluency is also well encapsulated in the Verbal Efficiency Theory (Perfetti, 1985) and later the Lexical Quality Hypothesis (Perfetti, 2007), which highlight the critical importance of high-quality representations of lexical and sub-lexical features (e.g., morphological features) for efficient recognition of words and word-to-text integration processes, and subsequently, textual comprehension. An issue that has received much less attention in the SVR literature, though, is morphological decoding, particularly fluent decoding based on morphemes (Carlisle, 2003;

Nagy, Carlisle, \& Goodwin, 2013), which is a focus of the next section.

\section{Morphology, Lexical Quality, and L2/Bilingual Readers}

\section{Morphology, Lexical Quality, and Target Language Experience}

English is known as a deep orthography with many irregularities regarding phoneme-

letter mapping (Katz \& Frost, 1992); yet, at a larger grain size level, it is far more regular

(Ziegler \& Goswami, 2005). For example, while -ive could be /iv/ (e.g., give) or /aiv/ (e.g., 
arrive), it is consistently the former as a suffix (e.g., objective). A lot of research has recently studied processes other than phonemic decoding in English reading development, notably processes based on morphemes, a larger size unit, for word decoding (Carlisle, 2003; Goodwin, Gilbert, \& Cho, 2013; Nagy et al., 2013). This body of research is in line with the fact that school English is replete with multimorphemic words (Nagy \& Anderson, 1984); and rapid recognition of those words is essential for readers to free up mental resources for higher-level processes to participate in text comprehension.

Many findings based on English-speaking readers suggest that older or more proficient readers are more adept at using morphemes for word decoding, and morphological decoding is developmentally more important than phonemic decoding (Carlisle \& Fleming, 2003; Deacon, Francis, \& Tong, 2017; Nunes, Bryant, \& Barros, 2012). Deacon et al. (2017), for example, found that Grade 5 children significantly outperformed Grade 3 children on derived word decoding and other morphological skills. Nunes et al. (2012) reported that 12-13-year old readers" "use of morphological units" $(\beta=.401)$, which included decoding real and pseudo derived words, explained a much larger proportion of variance in their reading comprehension than did the "use of graphophonic units" $(\beta=.157)$. Goodwin et al.'s (2013) crossed randomeffects item response modeling further revealed that adolescent readers' derived word decoding is under the joint influence of reader-characteristics, such as root knowledge and morphological 
awareness, and word-characteristics, such as derived-word and root-word frequency. These studies have all underscored the importance of morphological decoding; yet their findings have received little attention in the SVR literature where morphological decoding has been barely incorporated as a legitimate component of the decoding factor.

The importance of morphology in English reading can be particularly understood in light of the Lexical Quality Hypothesis, which posits that high-quality representation of phonological, orthographic, grammatical, and semantic features and the binding of these constituent features (i.e., constituent binding) are fundamental to efficient word recognition and word-to-text integration (Perfetti, 2007). Morphology has been highlighted as an important constituent binding mechanism to enhance lexical quality and thus has a strong implication for reading acquisition (Bowers, Kirby, \& Deacon, 2010; Kirby \& Bowers, 2017). This is notably the case in light of English derivation where suffixation often results in phonological and/or orthographic change, and change in the part of speech and meaning as well, to the base word to which a suffix is added (e.g., apply $\rightarrow$ applicable). Thus, morphological decoding, in particular fluent morphological decoding, should reasonably have a legitimate place, or developmentally an even more important place than phonemic decoding, in the SVR.

These theories and findings, while largely contextualized in L1 reading, pertain to L2 reading as well. In today's world, not everyone learns to become literate in English (or any 
language) following the same, traditional route where oral language proficiency, including language comprehension, is initially developed and brought into schooling where decoding and related skills are formally taught. Among other situations of L2 reading, there are, for example, those who do not speak at home the language for which they learn to develop their first or only literacy in school (e.g., English Language Learners or ELLs in the United States) (August \& Shanahan, 2006). In bilingual/multilingual societies, it is not uncommon for children to be required to become literate concurrently in two or more languages that could be typologically distant (García, 2008). These complexities have naturally led to a question as to how the SVR may accommodate L2 or bilingual reading.

In conceptualizing and studying L2 reading, researchers have paid attention to two particular issues: target language exposure (the focus here) and L1 influence (the focus of the next part), which work in tandem in shaping L2 reading (Koda, 2008). A typical characteristic of L2 reading, compared to L1 reading, is that readers are less exposed to the target language, which influences their reading development as well as the formation of skills that support reading development. An example is bilingual reading acquisition in Singapore, the context of this study. As we will revisit later in the Method section, Singapore adopts a bilingual education policy which mandates that all children learn to become bilingual and biliterate in English, which is also the medium of instruction, and their respective ethnic language or mother tongue (MT) 
(i.e., Chinese, Malay, and Tamil) (Dixon, 2005). This national policy for all does not mean that all children bring the same experience with English into their formal English literacy learning in school. While some children speak English as their dominant home language (hereafter, EL1), others speak their MT as the dominant home language (hereafter, EL2) and their English literacy learning commences without the level of English oral language support that characterizes reading acquisition in their EL1 peers (Yeong \& Rickard Liow, 2012; Zhang, 2017).

The differential experience of English language at home between EL1 and EL2 children has many implications on their early English reading acquisition (Yeong \& Rickard Liow, 2012). A notable implication is that EL2 children's oral language, including language comprehension, is generally weaker than that of their EL1 peers (Geva \& Farnia, 2012; Pasquarella, Gottardo, \& Grant, 2012). Additionally, their representations of sub-lexical features essential for learning to read in English, including, importantly, morphological features (e.g., roots and suffixes), are reasonably weaker as well, as discussed above (Chen, Ramirez, Luo, Geva, \& Ku, 2012; Kieffer \& Lesaux, 2012; Lesaux \& Siegel, 2003). Chen et al. (2012), for example, found that the derivational awareness of Grades 4 and 7 ELLs in Canada was significantly lower than that of monolinguals. This finding suggests that EL2 children may not be as actively reliant on morphological decoding as their EL1 peers during textual reading, although morphological skills have been found to be an important underpinning for literacy development in both groups (e.g., 
Goodwin, Huggins, Carlo, August, \& Calderon, 2013; Kieffer \& Lesaux, 2012; Ramirez, Chen, Geva, \& Kiffer, 2010). This issue, however, has been barely studied in the L2 or bilingual reading literature where the focus tended to be largely on the contribution of morphological awareness to word decoding rather than that of morphological decoding to reading comprehension.

\section{Linguistic Distance and Cross-linguistic Influence in L2 Reading}

The discussion above suggests that the two components of the SVR (i.e., decoding and language comprehension), particularly morphological decoding fluency, may function in reading comprehension differently in L2 readers. Although there seems to be a general consensus in the literature that the two-factor outlining of the SVR holds for L2 readers of English (e.g., Hoover \& Gough, 1990), some studies, none of which considered morphological decoding, have painted a complex picture, if not a more complex one, on some of the issues discussed earlier with primary reference to L1 readers (e.g., Geva \& Farnia, 2012; Lesaux, Crosson, Kieffer, \& Pierce, 2010; Pasquarella et al., 2012). Proctor, Carlo, August, and Snow (2005), for example, found that decoding fluency, as opposed to oral vocabulary and listening comprehension, was not a unique, significant predictor of fourth-grade Spanish-English bilingual children’ English reading comprehension. Pasquarella et al. (2012) reported that the contribution of decoding and vocabulary to reading comprehension significantly varied between Grades 9-10 L1 readers of 
English and L2 readers with diverse L1 backgrounds in Canada. While oral vocabulary was a significant, unique predictor in both groups, its contribution was far larger in the L1 group. Decoding, which included real and pseudo-word decoding fluency (TOWRE; Torgesen, Wagner, \& Rashotte, 1999), did not predict reading comprehension significantly in L1 readers; yet its effect on L2 readers' reading comprehension was significant.

Overall, although the L2 literature, like the L1 literature, has confirmed the importance of oral language in reading comprehension, decoding fluency seems to have raised a lot of questions that warrant further research. In particular, little research on the SVR has focused on morphological process of fluent decoding discussed earlier in this paper in light of L1 vs. L2 readers' differential experience in the target language, not to mention how variation may exist between L2 readers from different L1 backgrounds, for whom the influence from prior language and literacy processing experience is naturally expected (Koda, 2007).

Such an influence or cross-linguistic transfer effect, in addition to being supported by inter-lingual correlations between L1 and L2 in diverse groups of L2 or bilingual readers (e.g., Lam, Chen, \& Deacon, in press), has been well documented in Koda and colleagues' studies that compared written word recognition or lexical processing in adult English as a Second Language (ESL) learners with disparate L1 backgrounds (e.g., Hamada \& Koda, 2008; Muljani, Koda, \& Moates, 1998; Wang \& Koda, 2005). Those studies overall found that compared to ESL readers 
whose L1 was Chinese, which uses a morphosyllabic writing system, those readers whose L1 was alphabetic (e.g., Indonesian) showed consistently a processing advantage, in terms of faster responses, in lexical decision tasks that tapped sensitivity to English letter-phoneme mapping patterns. These findings point to a linguistic distance effect in that English L2 readers whose L1based processing shows congruence with what is required of English will enjoy a processing advantage.

Similar cross-linguistic effects have also been observed of morphology. Chinese is known to rely predominantly on compounding or concatenation of root morphemes for yielding new words. While there are some affix-like morphemes (e.g., 者 or 化), affixation in Chinese, unlike in English, is far from a productive process (Li \& Thompson, 1981; Packard, 2000). Additionally, in print, Chinese affixed words, like compound words, are represented in characters; the phonological and/or orthographic change characterizing English derivational suffixation, which was discussed earlier in light of lexical quality (e.g., phonological and orthographical features bound in morphology) (Perfetti, 2007), is barely applicable in Chinese. Cross-linguistic studies on derivational word processing in English L2 readers revealed that those whose L1 is characterized by a similar, productive derivational process like English (e.g., Spanish) showed a processing or developmental advantage, compared to their Chinese-speaking counterpart (see Clahsen, Felser, Neubauer, Sato, \& Silva, 2010 for a review). Koda (2000) 
found that compared to their Chinese peers, adult Korean ESL readers were significantly more efficient in deciding whether stimulus derivational words like invisible and include can be separated into two meaningful components (i.e., morphological segmentation). Likewise, Ramirez, Chen, Geva, and Luo (2011) found young Spanish-speaking ESL readers significantly outperformed their Chinese-speaking counterpart on a morphological task that asked participants to produce an appropriate derived form of a given base word to complete a sentence.

The implication of the above findings is apparent for the present study, which has a goal to compare the role of morphological decoding fluency in English reading comprehension between Chinese and Malay EL2 readers. Malay is a language of the Austronesian family used in Brunei, Malaysia, and Singapore. Like English, Malay is alphabetic, but unlike English, Rumi or the Romanized script of Malay belongs to a shallow orthography with highly regular letter-tophoneme correspondences. Derivation is a major way of word formation in Malay in addition to compounding and reduplication (Tadmor, 2009). There are about 25 derivational affixes in Malay, including prefixes (e.g., peng: ajar [to teach] $\rightarrow$ pengajar [teacher]), suffixes (e.g., $i$ : luka [wound] $\rightarrow$ lukai [to hurt]), and circumfixes (e.g., per...an: makan [to eat] $\rightarrow$ permakanan [the habit of eating]). Notably there are two prefixes me- (marking active verbs) and pe- (deriving agents) for which different allomorphs (men-, mem-, meng-, and meny- for me-; and pen, pem-, peng-, and peny- for pe-) are used depending on the initial letter of the base word. Derivation is 
an important consideration in Malay-speaking children's reading acquisition and school curriculum (Ministry of Education, 2014b; Rickard Liow \& Lee, 2004). If, as previous studies have found, L1's linguistic proximity in derivation gives L2 readers of English a processing advantage, it seems reasonable to expect that compared to their Chinese EL2 peers, Malay EL2 readers in Singapore would, as a result of their Malay processing and instructional experience, show more active engagement with morphological process of decoding in English reading.

\section{Research Questions}

Although the literature has provided some insights into the complexity of the SVR in L2 readers, little research has focused on morphological decoding fluency as a potential addition to the decoding component. In particular, little research has concurrently considered target language experience and cross-linguistic influence in the role of decoding and oral language in L2 English reading comprehension by comparing readers from disparate L1 backgrounds. This study aimed to address this gap and answer the following two questions:

RQ1: How may the contribution of morphological decoding fluency and oral vocabulary to reading comprehension differ between fourth-grade bilingual readers of English with differential English language experience at home? We predicted that for both EL1 and EL2 readers, oral vocabulary would be a significant unique predictor given the centrality of meaning in reading comprehension and the convergent findings reviewed earlier of previous studies. In 
addition, we predicted that over and beyond phonemic decoding, morphological decoding fluency would make a lesser contribution in EL2 than in EL1 readers because of EL2 readers' limited exposure to English at home and thus less strong morphological representations.

RQ2: How may the contribution of morphological decoding fluency and oral vocabulary to reading comprehension differ between fourth-grade EL2 readers with different ethnic language backgrounds (i.e., Chinese vs. Malay)? We predicted that oral vocabulary would be a significant, unique predictor disregarding readers' ethnic language background based on the same rationale presented above; over and beyond phonemic decoding, morphological decoding fluency would make a lesser contribution in Chinese EL2 than in Malay EL2 readers. The latter prediction was based on the linguistic distance analyzed earlier between Chinese/Malay and English (i.e., derivation is characteristic of English and Malay but not Chinese) and the findings reviewed of previous cross-linguistic studies on ESL readers from different L1 backgrounds.

\section{Method}

\section{Participants and Research Context}

The participants were three groups of Grade 4 bilingual children. For the purpose of this paper, they were selected from a larger pool of participants in a longitudinal project that examined bilingual reading development in children of different ethnicities in Singapore. (See, for example, Zhang, 2017; Zhang, Koda, Leong, \& Pang, 2019.) Singapore is a multi-ethnic and 
multilingual country where the population is comprised of three major ethnic groups, that is, Chinese, Malay, and Indian, with ethnic Chinese being the largest group. When the longitudinal project first started in Grade 3, there were, according to the record of the three participating schools, a total of 677 students studying in 19 classes. Among them, 415 were studying Chinese as the MT subject. While a large majority of those Chinese-studying students were ethnic Chinese born in Singapore, they also included a small number of children of ethnicities other than Chinese (e.g., Korean) who were born in Singapore and children who immigrated to Singapore after birth in another country (e.g., China or South Korea). Likewise, the school record showed that 220 students were studying Malay as their MT. Those students also included a small number who were not born in Singapore but immigrated from another country (e.g., Malaysia or Indonesia). The rest of the student pool included 28 who were learning Tamil, Hindi, or Bengali as their MT and 14 others who, for reasons unknown, were not studying any MT.

The participants of the analysis reported in this paper were ethnic Chinese and Malays who showed different patterns of language use at home. They were purposively selected from the larger pool of Chinese- and Malay-studying students described above. When data was first collected at the end of Grade 3, a questionnaire was administered to parents to elicit children's home language use patterns. Each parent was asked on the questionnaire, among other choices of language use patterns, whether they spoke MT or English as a dominant language or whether 
they had balanced use of the two languages at home. Because the questionnaire was designed for parents of different ethnic backgrounds, it was presented in English. An ethnic Chinese parent should easily interpret MT presented on the questionnaire as referring to Chinese, which is known to Singaporeans as consisting of Mandarin as well as other varieties of Chinese such as Cantonese, Hokkien, or Teochew. These varieties, which may not be mutually intelligible, share the same morphosyllabic writing system. Likewise, an ethnic Malay parent should easily interpret MT as referring to Malay.

The selection of students to form a database for this study followed the following steps. For the Chinese-studying group, 90 of the 415 students were excluded who did not include all English literacy measures at the end of Grade 4, the source of data on which this study was based. ${ }^{3}$ The remaining 325 students were then subcategorized into different groups based on the language use patterns collected from the questionnaire. For the purpose of this paper, a child was considered EL1 if both parents used English as the dominant language or one parent used English as the dominant language and the other had balanced use of Chinese and English. Likewise, a child was considered EL2 if both parents used Chinese as the dominant language or one parent used Chinese as the dominant language and the other had balanced use of Chinese and English. Consequently, 74 ethnic Chinese children were identified as EL1 (Age $=10.4$ years) and 105 as EL2 $($ Age $=10.5) .{ }^{4}$ The same steps were followed to identify Malay-studying 
children for the present study. Among the 166 Malay-studying students, 28 were identified as

EL1 and 60 as EL2 $($ Age $=10.4)$. The Malay-studying EL1 children were not included in this study because the sample was considered too small for path analysis. ${ }^{5}$

\section{Assessments}

A variety of tasks were administered to assess the participants' English and MT reading and related abilities at the different stages of the project on which the current study was based.

Most abilities were assessed three times, that is, at the end of Grade 3, the middle of Grade 4, and the end of Grade 4. Instruments related to this study included the questionnaire mentioned earlier and the tasks described in detail below. The questionnaire and the nonverbal intelligence task were administered once at the end of Grade 3. The English literacy tasks were administered at the end of Grade 4. This paper draws upon the literacy data collected at the end of Grade 4 because only in this third round of data collection was phonemic decoding assessed.

Non-verbal intelligence. Non-verbal intelligence was assessed with the first three sets or 36 items of the Raven's Standard Progressive Metrices (Raven, Raven, \& Court, 1998). The internal consistency reliability or Cronbach's $\alpha$ was $.836, .874$, and .896 for the Chinese EL1, Chinese EL2, and Malay EL2 groups, respectively.

Phonemic decoding. The Word Attack section of the Woodcock Reading Mastery Tests - Revised (Form H; Woodcock, 1998) was administered by trained research assistants, together 
with the morphological decoding fluency task described below, individually in a quiet place in the participants' respective schools. The first 36 pseudo words were selected in consultation with the participants' teachers and with reference to the Grade Equivalent information on the test scoring form so as to avoid any unnecessarily difficult set of items. The ceiling rule, that is, "continue until the six highest-numbered items administered are failed," was not applied in that all 36 items were administered to all participants. Although the standard procedure was not followed, it was not believed to pose any threat to the validity of this study because our purpose was to document individual differences in phonemic decoding in the participants instead of having any additional purpose to document the specific Grade Equivalent and the Relative Proficiency Index (RPI) of each participant for any diagnostic purpose. An item correctly pronounced received one point, with the maximum score possible being 36 . This measure not only provided information on the contribution of phonemic decoding, as conceptualized in the SVR, to reading comprehension, but also served as an important covariate when the unique effect of morphological decoding fluency was tested. Cronbach's $\alpha$ for the Chinese EL1, Chinese EL2, and Malay EL2 groups was .804, .914, and .898, respectively.

Morphological decoding fluency. This study focused on morphological decoding fluency rather than basic accuracy because speed of processing is inherently encapsulated in lexical quality, which was outlined earlier in discussing the influence of bilingual readers' 
differential target language experience on their lexical and sub-lexical representations and reading acquisition. This skill was measured with a researcher-developed task that consisted of 60 English derivational words printed on paper (see Appendix). Similar tasks, albeit untimed, have been previously used to measure English morphological decoding (e.g., Deacon et al., 2017; Nunes et al., 2012). They included both words where there is no change to the pronunciation and spelling of the base word to which an affix is added (e.g., movement) and words where there is pronunciation and/or spelling change (e.g., dramatic, partial). Participants were instructed to read the words as fast and as accurately as possible in 30 seconds without skipping any word. They were given six words to practice as many times as they felt needed before they moved onto the test words. Each correctly pronounced word received one point; the maximum score possible was 60 . The test-retest reliability (i.e., the correlation between the current measurement and the previous one in the middle of Grade 4) was .756 .871 , and .805 for the Chinese EL1, Chinese EL2, and Malay EL2 groups, respectively.

Oral vocabulary. In this study, oral, receptive vocabulary knowledge was used to represent participants' language comprehension ability (Catts, 2018). It was measured with the fourth edition of the Peabody Picture Vocabulary Test or PPVT-IV (Dunn \& Dunn, 2007). Because the participants were bilingual readers of English, Set 7 (Start Age 8) instead of Set 8 (Start Age 9) was chosen when they were first tested in Grade 3 (about 9.5 years old). Five sets 
(Sets 7-11) with a total of 60 words were chosen such that adequate variance of vocabulary knowledge could be captured in the participants for path modeling.

The items were administered in a whole class format with the easel presented on an overhead projector to accommodate the time constraint of data collection. All words were read aloud to the participants, and they were to circle the number of the picture, out of four on an answer sheet, that represented the meaning of a word heard. The Ceiling Set Rule, "8 or more errors in a set. Stop testing after giving all items in the Ceiling Set," was not applied in that all participants responded to all 60 items without involving any diagnostic procedure. As in the case of the phonemic decoding task, this was not believed to threaten the validity of the study, which aimed to document individual differences in the participants without any additional purpose to profile each of them (e.g., age or grade equivalent). Each correct choice received one point; the maximum total score possible was 60 . Cronbach's $\alpha$ was $.822, .895$, and .900 for the Chinese EL1, Chinese EL2, and Malay EL2 groups, respectively.

Passage comprehension. Reading comprehension was measured with a passage comprehension task which consisted three grade-appropriate passages with a mean length of about 300 words. One of the passages was narrative (i.e., a story about a shepherd and the King) and the other two informational (i.e., on the life of Mark Twain and wolves, respectively). Each passage was followed by five multiple-choice questions measuring different comprehension 
skills (e.g., co-referential relationship, textual inferencing, main idea). Each correct choice for a question received one point with the maximum score possible being 15 . The passages were adapted from a reader for elementary school students (Beck, 1989) with the questions researcherdeveloped. This task was part of a larger one developed for an earlier study on Chinese-English biliteracy development in Grades 3-5 Chinese-speaking ESL learners in the United States.

Cronbach's $\alpha$ for the present study was $.724, .768$, and .709 for the Chinese EL1, Chinese EL2, and Malay EL2 groups, respectively.

\section{Data Analysis Methods and Procedure}

The primary data analysis method was path analysis, which was performed on Mplus 7

(Muthén \& Muthén, 1998-2015). First, a path model (see Figure 1) was constructed and tested

for each group. In the model, phonemic decoding, morphological decoding fluency, and oral

vocabulary were predictors of passage comprehension; nonverbal intelligence was included as a covariate. The inclusion of phonemic decoding in the model was important because children could engage with both phonological and morphological decoding for words in a written text.

Phonemic decoding was also hypothesized to predict morphological decoding fluency because

letter-to-phoneme conversion could be involved in decoding derivational words given the

alphabetic nature of English. A converse predictive relationship, however, was not hypothesized because conceptually morphological process would not contribute to decoding pseudo words in 
the Word Attack task. Finally, oral vocabulary was hypothesized to predict both decoding measures in that a larger oral vocabulary implies greater phonemic awareness and thus greater phonemic decoding (Ouellette, 2006) and that the morphological decoding fluency task was comprised of real derivational words where knowledge of a whole word, in addition to that of its morphemic constituents, could facilitate the decoding of it.

In addition to significance testing based on $\chi^{2}$, goodness of model fit was evaluated based on the Comparative Fit Index (CFI), the Standardized Root Mean Square Residual (SRMR) and the Root Mean Square Error of Approximation (RMSEA). Hu and Bentler (1999) suggested that cutoff values of CFI $>.95$, RMSEA $<.06$, or SRMR $<.08$ indicated a model with very good fits.

To directly answer the research questions, multi-group path analysis based on $\chi^{2}$

difference testing was conducted between the two Chinese groups (EL1 vs. EL2) on the one hand and between the two EL2 groups (Chinese vs. Malay) on the other. In addition, commonality analysis (Nimon, 2010) was conducted to gauge the unique effect of each predictor of reading comprehension (i.e., the unique proportion of variance explained), particularly morphological decoding fluency, in each group and across the three groups.

\section{Results}

\section{Task Performance and Bivariate Correlations}


Table 1 shows the participants' performance on all the measured competencies with the skewness and kurtosis estimates of each variable. Those estimates were in general below the rule-of-thumb values for univariate normality (i.e., \pm 2 for both skewness and kurtosis) and the critical values found to result in significant deviation from multivariate normality (i.e., \pm 2 for skewness and \pm 7 for kurtosis) (Curran, West, \& Finch, 1996). A series of one-way ANOVA with the Bonferroni correction showed a significant difference in all four measures between the three groups (all original $p \mathrm{~s}<.001$; all adjusted $p \mathrm{~s}<.0125$ ). Post-hoc analyses with the Bonferroni adjustment were then performed. For phonemic decoding, the Chinese EL2 group scored significantly lower than the Chinese EL1 and Malay EL2 groups; the latter two groups did not differ significantly. For all three other measures, including morphological decoding fluency, oral vocabulary, and reading comprehension, the Chinese EL1 group significantly outperformed the other two groups; between the two EL2 groups, however, there was no significant difference.

Insert Table 1 about here

Table 2 shows the bivariate correlations between the measured competencies in each group. All the four literacy measures were significantly correlated. To highlight, oral vocabulary correlated with reading comprehension significantly in all three groups $(p \mathrm{~s}<.001)$. Both 
phonemic decoding and morphological decoding fluency correlated significantly with reading comprehension across the three groups; yet, the magnitude of the correlation of morphological decoding fluency with reading comprehension was higher than that of phonemic decoding in both (Chinese) EL1 and Malay EL2 groups. A converse pattern, however, was found in the Chinese EL2 group. Finally, the correlation between phonemic decoding and morphological decoding fluency was notably high in the Chinese EL2 group $(r=.817, p<.001)$ and higher than in the other two groups, which seems to suggest that Chinese EL2 readers might have applied similar processes when decoding pseudo words and (real) derivational words (i.e., processes based on letter-sound correspondences for both types of words).

Insert Table 2 about here

\section{RQ1: Comparing Chinese EL1 and EL2 Readers}

To answer the first research question, the path model shown in Figure 1 was run for the Chinese EL1 and EL2 groups respectively, and the models of the two groups were then compared based on commonality analysis and multi-group path analysis.

As shown in Table 3, for both groups, the path model showed very good model fits. The four predictors, including nonverbal intelligence as a covariate, explained $51.1 \%$ and $38.3 \%$ of 
the variance in reading comprehension in the EL1 and EL2 groups, respectively. Table 4 shows the standardized estimates of the path coefficients; further details are shown in Figures 1a and 1b. In both groups, oral vocabulary was a unique, significant predictor, $\beta=.287, p=.005$ and $\beta$ $=.389, p<.001$ respectively for the EL1 and the EL2 group. In the EL1 group, after controlling for phonemic decoding and oral vocabulary, morphological decoding fluency was a significant predictor of reading comprehension $(\beta=.516, p<.001)$; this effect, however, was not significant in the EL2 group $(\beta=.036, p=.793)$. Over and above morphological decoding fluency and oral vocabulary, phonemic decoding did not significantly predict reading comprehension in both groups, $\beta=.034, p=.772$ and $\beta=.288, p=.051$, for the EL1 and the EL2 group, respectively. Commonality analysis further showed that in the EL1 group, morphological decoding fluency explained about $14.2 \%$ of the unique variance in reading comprehension, whereas in the EL2 group, the proportion was minimal (see Table 4). Overall, these patterns, while confirming the centrality of language comprehension in reading comprehension disregarding reader group, showed different involvement of decoding in that the EL1 readers, as opposed to the EL2 readers, prioritized morphological decoding fluency in reading comprehension.

Insert Tables $3 \& 4$ about here 
Insert Figure 1 about here

Multi-group path analysis was subsequently performed to compare the magnitude of the effect of morphological decoding fluency on reading comprehension in the two groups. The baseline model, which allowed all parameters to be freely estimated, showed very good model fits, as shown in Table 3. A modified model was then tested with the path coefficient of morphological decoding fluency constrained to be the same between the two groups. This modified model overall also showed good model fits; yet, it also showed significant deviation from the baseline or non-constrained model, $\Delta \chi^{2}(1)=10.461, p<.001$. The null hypothesis was thus rejected and a conclusion made that the magnitude of the path coefficient was significantly different between the two groups, higher in the EL1 group and lower in the EL2 group.

\section{RQ2: Comparing Chinese EL2 and Malay EL2 Groups}

The same procedure of analysis was followed to answer the second research question.

The path model for the Malay EL2 group showed good model fits; and the four predictors together explained $49.8 \%$ of the variance in English reading comprehension (see Table 3). Like in the two Chinese groups compared earlier, oral vocabulary was a unique, significant predictor of Malay EL2 readers' reading comprehension $(\beta=.321, p=.004)$. The unique effect of 
phonemic decoding, however, was not significant $(\beta=.171, p=.169)$. Like in Chinese EL1 but not Chinese EL2 readers, morphological decoding fluency was a unique, significant predictor in Malay EL2 readers $(\beta=.334, p=.010)$. Commonality analysis revealed that morphological decoding fluency explained about 5.4\% of unique variance in Malay EL2 readers' reading comprehension, which was smaller than in Chinese EL1 readers but higher than their Chinese EL2 peers (see Table 4).

The baseline multi-group path model showed good model fits (see Table 3). The constrained model, with the path coefficients of morphological decoding fluency to reading comprehension constrained to be the same, also showed good model fits. This new model, however, deviated significantly from the baseline model, $\Delta \chi^{2}(1)=5.156, p=.023$. The null hypothesis was thus rejected; and it was concluded that the effect of morphological decoding fluency was significantly greater in Malay EL2 than in Chinese EL2 readers. Taken together, these findings suggest that Malay EL2 readers, like (Chinese) EL1 readers but unlike Chinese EL2 readers, prioritized morphological decoding in English reading comprehension.

\section{Discussion}

This study aimed to unravel the complexity of the SVR in bilingual readers of English with a focus on the decoding component, particularly morphological decoding fluency. It addressed the influence of two major factors in L2 reading development, that is, target language 
experience and cross-linguistic influence, by comparing three groups of young English readers

who had different home language experiences in a multilingual context.

\section{Influence of Differential Target Language Experience}

Path analysis showed that for both the Chinese EL1 and EL2 groups, oral vocabulary was a unique, significant predictor of reading comprehension, over and above the two decoding measures. This finding is in line with the spirit of the SVR where oral language comprehension is a major component. Together with a similar finding on the Malay EL2 group, which is discussed in the next section, it suggests that disregarding readers' target language experience, or whether or not school reading acquisition happens with adequate home language support, knowledge of meaning is fundamental in reading comprehension. This finding also corroborates those of previous studies on L1 readers of English as well as readers of English as an additional language (e.g., Pasquarella et al., 2012; Proctor et al., 2005).

It was on the decoding component that the two groups differed. Morphological decoding fluency, in particular, painted a complex picture about the SVR. Specifically, morphological decoding fluency, as opposed to phonemic decoding, surfaced as a unique, significant predictor of reading comprehension in the Chinese EL1 group; yet this significant effect was not found in the Chinese EL2 group. The magnitude of the effect was also significantly greater in the EL1 
than in the EL2 group. Overall, the EL1 group, as opposed to their EL2 peers, seemed to have prioritized morphological decoding fluency during textual reading.

In this study, although the two Chinese groups learned English literacy in the same school context, the EL1 group spoke English as their dominant home language, which gave them more exposure to English. Compared to their EL2 peers whose dominant home language was Chinese, the EL1 readers reasonably had had more morphological processing experience and thus stronger representations of morphological features of English or greater lexical quality (Perfetti, 2007). The priority they gave on using morphemes, a larger grain size unit (Ziegler \& Goswami, 2005), for fluent decoding also corroborates earlier findings on native Englishspeaking children's reading acquisition that morphological decoding was developmentally more important than phonemic decoding (Carlisle, 2003; Nunes et al., 2012).

In contrast, the Chinese EL2 readers, when encountering words in print, seemed to rely more on phonemic decoding (see the much greater path coefficient of phonemic decoding in Table 4), possibly because this skill is underscored in their English curriculum (Ministry of Education, 2008). The lack of a significant, unique effect of morphological decoding fluency, however, should not be interpreted to mean that this process is unfunctional in English reading comprehension in Chinese EL2 readers. After all, previous findings on young Chinese-speaking ESL readers in English-speaking societies like the US or Canada have highlighted the 
importance of morphology (e.g., Lam, Chen, Geva, Luo, \& Li, 2012; Wang, Cheng, \& Chen, 2006). Developmentally, it might be the case that Chinese L2 readers in a bilingual context like Singapore, in contrast to their counterparts in a mainstream English-speaking society like the US, may show a delayed emergence of active derivational morphological processes in reading. This issue is revisited later when we discuss limitations and directions for future research.

\section{Cross-linguistic Influence}

Cross-linguistic influence in L2 reading has been widely documented (Koda, 2007, 2008). Psycholinguistic experiments on visual word processing in skilled, adult ESL readers with disparate L1 backgrounds have consistently shown a processing advantage of those whose L1 lexical processing involves a similar process that characterizes the processing in English (e.g., Muljani et al., 1998). A few studies on young, developing ESL readers revealed similar findings (e.g., Chen et al., 2012; Ramirez et al., 2011). Little research on modeling the SVR in L2 readers, however, has incorporated this perspective and compared readers of different L1 backgrounds to reveal possible variation in the contribution of the decoding component, particularly morphological decoding fluency, to reading comprehension. One objective of this study was to address this gap. Although oral vocabulary was found to be a unique, significant predictor of reading comprehension in both EL2 groups, there was a notable difference in decoding. In the Malay EL2 group, morphological decoding fluency surfaced as a unique, significant predictor, a 
pattern similar to that of the (Chinese) EL1 group where morphological process of decoding was prioritized over phonemic decoding. It was also found to play a larger role in predicting reading comprehension in the Malay EL2 group than in the Chinese EL2 group.

Given the two EL2 groups studied English literacy in the same school context, the different patterns could logically be accounted for from the perspective of the difference in their ethnic language. Malay is an alphabetic language with rich derivational processes (Tadmor, 2009), which makes it linguistically close to English in terms of morphological processing. In this regard, the Malay EL2 readers, who used Malay as their dominant home language and learned to read Malay (concurrently with English) in school, presumably had more refined derivational representations (i.e., greater lexical quality) and thus enjoyed an advantage in applying morphological process for fluent decoding of English derivational words, compared to their Chinese EL2 counterpart, whose ethnic language shows notable difference from English in derivation. Consequently, it was no surprise that the involvement of morphological decoding fluency in reading comprehension was greater in Malay EL2 readers than in Chinese EL2 readers. This finding also seems to corroborate an earlier study where intra- and inter-lingual predictors of L2 English reading fluency was compared between young Spanish-English and Chinese-English bilingual readers (Pasquarella, Chen, Gottardo, \& Geva, 2015). In that study, the former group's L1 word decoding fluency explained a substantial amount of unique variance 
in their English word decoding fluency (over 18\%), whereas little unique variance was explained in the latter group (about 2\%) (see Table 8 in Pasquarella et al., 2015). ${ }^{6}$

\section{Limitations and Future Research}

Several limitations are noted. To begin with, in this study, oral vocabulary was used to represent the participants' oral language comprehension. While this has been not uncommon in the literature on the SVR, perhaps because of the very high correlation between oral vocabulary and listening comprehension (Catts, 2018), the evaluation of the SVR in bilingual readers would be more rigorous with listening comprehension measured and modeled with the two decoding measures of this study. The lack of a direct measure of language comprehension may be a reason that the three oral language and decoding measures only explained a moderate amount of variance in reading comprehension in this study. This, however, may also imply that English reading acquisition in L2 or bilingual children is less accommodated by the SVR.

Another limitation pertains to the sample of the Chinese EL1 and the Malay EL2 group being relatively small. We did not include the Malay EL1 group in the analysis, because the number of the sample was very small. The analysis for answering the first research question would be augmented with an additional comparison between the Malay EL1 and EL2 groups (or perhaps even better together with a monolingual English-speaking comparison group). A relevant question to answer through such a comparison would be whether Malay EL1 readers, 
because of their greater exposure to English at home, would rely even more on morphological process of decoding, in comparison to their Malay EL2 peers. ${ }^{7}$ Comparing English L2 readers in different societal contexts could be another direction for future research.

Additionally, a phonemic decoding fluency task (e.g., TOWRE; Torgesen et al., 1999) and a second and untimed morphological decoding measure could be included to tease apart basic accuracy and fluency of decoding based on different processes (i.e., phonemic vs. morphological) so that a deeper insight could be generated into any more specific difference that may lie between EL1 and EL2 readers on the one hand and between EL2 readers from different ethnic language backgrounds on the other. Longitudinal research would also be desirable in the future. A limitation of this study is its focus on fourth grade only. A question for future research is whether developmentally the patterns identified of the participants would change; more specifically, whether a similar pattern in the Chinese EL1 group would emerge in the EL2 group, as the EL2 group's English literacy develops over time. Longitudinal research, in this respect, would also help clarify an issue that the different patterns found of the three groups of readers may be related to a possibility that the readers differed in their developmental phases.

In this study, close attention was not given to the connection between the oral vocabulary and decoding measures because it was not a focus of the present study. One issue that might raise a concern is that the morphological decoding measure was not purely decoding but had semantic 
involvement. After all, morphemes are a meaning-bearing unit, and morphological knowledge develops along with oral language development; and morphological decoding in this study was measured with real words. In this respect, morphological decoding and oral vocabulary/language are unavoidably connected (see Goodwin et al., 2013). Although previous studies tended to focus on "pure decoding" by relying on measures of pseudo word decoding (e.g., the Word Attack task of the present study), we argue that models of reading need to accommodate developmental changes; and thus, morphological decoding, which has been found to be developmentally more important than phonemic decoding in English reading acquisition (e.g., Nunes et al., 2012), should be a valuable component for examining the decoding component of the SVR in the future. One way that may reduce any potential involvement of vocabulary, though, would be to use pseudo derived words (e.g., mishammer and amazive; Nunes et al., 2012) for measuring morphological decoding fluency.

Finally, although this study drew upon the SVR to compare the three groups of bilingual readers of English, the SVR only "describes the proximal influences on reading” (Kirby \& Savage, 2008, p. 76). Each of its two components (or "upper-level skills;" Kim, 2017, p. 326), namely, decoding and listening comprehension, is underpinned by a number of distal but highly important sub-skills. (Word decoding, for example, is influenced by many "lower-level” subskills like phonemic and morphological awareness, which is true for both L1 and L2 reading 
[e.g., Goodwin, Huggins et al., 2013; Mahony, Singson, \& Mann, 2000; Ramirez et al., 2010].)

This is well depicted in Scarborough's (2001) "rope" model of skilled reading ("The Many

Strands that are Woven Together in Skilled Reading;" p. 98). Those sub-skills influence not only

the two components themselves but also reading comprehension in very complex ways (e.g.,

Kim, 2017; Vellutino, Tunmer, Jaccard, \& Chen, 2007). For example, Kim (2017) found, in light

of a "DIER (Direct and Indirect Effect Model of Reading) Model," that word reading and

listening comprehension mediated the influence of a number of language and cognitive

component skills (e.g., vocabulary and inference) in young English-speaking children. This

finding suggests that while the SVR is simple in its two-component structure, there are complex

issues to examine about the influence of proximal as well as distal factors on reading

comprehension. To gain a deeper understanding about the complexity of English reading in L2

or bilingual readers, more complex designs and modeling should be needed in the future.

\section{Conclusions and Implications}

This study reexamined the SVR in bilingual readers of English with a particular focus on

morphological decoding fluency as a possible addition to the decoding component. Specifically,

it examined the influence of target language experience and L1 background on the SVR by

comparing three groups of bilingual readers learning English literacy in the same school and

societal context but with different home language backgrounds. Across all three groups, Chinese 
EL1, Chinese EL2, and Malay EL2, oral vocabulary was consistently a unique, significant predictor of reading comprehension; morphological decoding fluency surfaced as a unique, significant predictor in the Chinese EL1 and Malay EL2 groups but not the Chinese EL2 group. The findings suggested that morphological decoding fluency should developmentally be an important addition to the decoding component for examining the SVR in bilingual readers of English or English reading acquisition in general. This is in line with the findings in the L1 literature that morphological decoding is increasingly more important than phonemic decoding in English reading acquisition. In this respect, the findings have enriched the current understanding of the SVR as simple but complex (Kirby \& Savage, 2008). They also enrich the literature on the role of morphology in English reading development where word decoding measures do not often give due attention to morphologically complex words (see Nunes et al., 2012 for an exception). The purposive focus of this study on derivational words for the decoding fluency measure is particularly noteworthy in that derivational affixes encode syntactic information of English words thereby readers can parse sentences more efficiently during textual reading (Nagy, 2007). Recently there has been an emerging interest in the contribution of syntactic awareness to English reading comprehension (e.g., Deacon \& Kieffer, 2018). In light of this line of interest and syntactic aspects of morphology (Tyler \& Nagy, 1989), morphologically complex words should deserve special attention in research on English reading comprehension. 
Finally, the findings provide direct evidence for the theorization of L2 reading development that highlights the joint functioning of target language experience and crosslinguistic influence (Koda, Lü, \& Zhang, 2014): Without a processing benefit from L1 (e.g., the Chinese EL1 and EL2 groups in this study), target language experience would have a determining effect on how a process functions in reading development; on the other hand, when target language experience is similarly constrained like in the Malay and Chinese EL2 cases, variation in L1 would make a difference.

Pedagogically, the findings, while pointing to the importance of oral language in English reading development, highlight that it is important to engage children with multiple processes, over and beyond the process based on letter-sound correspondences, for fluent decoding in English textual reading; and differential instructional support is needed for L2 readers with disparate L1 backgrounds depending on the linguistic distance from or the proximity with the target language. While the unique effect found of morphological decoding fluency on reading comprehension was overall not big in those fourth-grade bilingual readers of English in this study, the increasing prevalence of morphologically complex words (especially, derivational words) in school English (Nagy \& Anderson, 1984) suggests that developmentally, decoding based on morphemes or the larger grain size unit (Ziegler \& Goswami, 2005) should be a goal for sustained instruction. The limited engagement with morphological decoding in reading 
comprehension found of the Chinese EL2 readers in this study, which seemed to be a result of influence from Chinese (i.e., limited affixation), suggests that direct morphological instruction should be particularly important for those readers, over and beyond instruction that aims to promote their sensitivity to English phonemes and letter-to-phoneme correspondences.

Although this study was conducted with bilingual readers of English in Singapore, the implications for English literacy instruction are far wider. A notable case in point outside of the Singaporean context is instruction for ELLs or emergent bilinguals in North America where schools are becoming increasingly linguistically diverse. Thus, linguistically responsive instruction that considers ELLs' diverse linguistic experiences in both English and ethnic language(s) is essential. For example, explicit instruction on English derivation seems particularly necessary for Chinese-speaking ELLs; and for Spanish-speaking ELLs, derivational principles and cognates in Spanish are an important instructional resource for promoting their English language and literacy development (see also Hernández, Montelongo, \& Herter, 2016). 


\section{Notes}

This research was supported by a grant (OER24/10 ZDB) awarded to Dongbo Zhang from the Office of Education Research, National Institute of Education, Nanyang Technological University. The views and opinions expressed in this article are ours only and do not represent those of the funder. We thank the anonymous reviewers for their constructive comments and are particularly indebted to Robert T. Jiménez and Amanda P. Goodwin, Editors of Reading Research Quarterly, for guiding us through the revision and resubmission process. Any errors remain ours.

1. The LC component has been referred to as listening comprehension (e.g., Gough \& Tunmer, 1986), language comprehension (e.g., Chen \& Vellutino, 1997), oral language comprehension (e.g., Kirby \& Savage, 2008; Tunmer \& Chapman, 2012), and linguistic comprehension (e.g., Hoover \& Gough, 1990). It was also often operationalized and measured in different ways across individual studies. This paper, while recognizing LC's diverse naming in the literature, uses it refer to the comprehension and understanding of spoken language.

2. A number of language-related terms are used in this paper where English reading acquisition is theorized, different language backgrounds of the participants described, or the linguistic and educational discourse in Singapore presented. These terms include mother tongue, dominant language, L1, L2, first language, second language, target language, and bilingual. Defining 
these terms in precise terms to show clear distinctions seems impossible and unnecessary, because the meanings of these terms could vary depending on the specific context of their use in the research literature, and some of these terms have been encoded with unique meanings in the particular sociolinguistic and educational context in Singapore. The following clarifications, therefore, are intended as general information for the reader to better understand the context and the rationale of this study. For a historical perspective on language policy or language-ineducation planning in Singapore, refer to Dixon (2005) and Shepherd (2005).

To begin with, Mother Tongue (MT) is a term used in the political and educational discourse in Singapore, including government policy documents and school curriculum, to refer to the ethnic languages of the country's three major ethnic groups (i.e., Chinese, Malay, and Indian). It is so-called because it is encoded with a strong value of culture and heritage of these groups. Although Singaporean students are required to learn their respective MT in school, it is not necessarily the language that is first learned or the dominant home language for all in the present Singapore society. As a result of gradual home language shifts in Singapore, some children actually first learn and use English as opposed to their MT. A term that may be similar in meaning in this respect would be heritage language. This paper uses Mother Tongue and follows how it is locally defined and used in Singapore instead of "borrowing" a term like "heritage language," which is primarily used in North America to refer to the heritage/ethnic 
language of immigrant families. We argue that such "borrowing” would be unnecessary and could be misleading.

When we present some theoretical and empirical literature on reading in an additional/non-societal language, we have used terms like first language (L1) and second language (L2) in their general or conventional senses, that is, first language is the language that one acquires and uses first, whereas second language is learned after one has learned their first language (Richards \& Schmidt, 2002). These general senses, however, would not precisely describe the different groups of readers in this study. It would actually be misleading to do so, not only because the temporal order implied in first and second does not pertain precisely to the reality of bilingual learning and use in Singapore but also because in the political and educational discourse in Singapore, the first vs. second distinction is actually defined in light of the importance ascribed to a language. To be specific, Singaporeans' first language, as defined in government documents and school curriculum, is English; and a MT language is a second language. This is because English is the medium of school instruction, the lingual franca for communication across diverse ethnic groups, and the language for science, technology, business, and so on, whereas MT is primarily for the maintenance of cultural heritage and is thus less important than English. (To avoid any confusion that might be incurred in international readers about the first vs. second language distinction used in Singapore, Pakir [1992] proposed to call 
English and MT as first school language and second school language, respectively.) For these reasons, in this paper, following reading scholars in Singapore like Richard Liow and colleagues (e.g., Yeong \& Rickard Liow, 2012), we have carefully chosen to name the different groups of participants as EL1 or EL2 based on language dominance at home: "1" in EL1 denotes that English is the dominant language; likewise, "2" in EL2 means MT is the dominant language. In light of the aforementioned clarifications on L1 vs. L2 and EL1 vs. EL2 distinctions, Singaporean students are bilingual users or readers with differential English language experience at home. As described in further detail in Note 5 later, all students in Singapore are taught to become bilingual and biliterate in English and their respective MT through concurrent instruction in school. For this reason, although the fourth graders in this study differed in their exposure to English at home, we think "bilingual readers of English" more accurately describes who they are than would L1 vs. L2 readers of English.

Finally, target language is used in this paper primarily to refer to the focal language under discussion or the "target" for learning and instruction (i.e., English). In some places of the paper where the theoretical or empirical literature on cross-linguistic influence in L2/bilingual reading is reviewed and discussed, target language carries its conventional sense of use in the language acquisition literature, that is, a target language is a second/foreign language for learning. This sense may seem to pertain to the EL2 readers in this study; yet, it would not seem 
to describe the EL1 readers well. Nevertheless, for both EL1 and EL2 readers, English, the focal language of this study, was the "target" of their learning and reading development; and the two groups differed in their "target language" experience at home.

3. There were varied, random reasons. For example, some did not consent to participate; others participated initially at Grade 3 but were not later tested at the end of Grade 4 for reasons like absences from school.

4. A large majority of the rest $(N=106)$ were those who reported patterns of more balanced use of Chinese and English at home (e.g., one parent, one language). They also included a small number of those who used a language other than English and Chinese (e.g., Korean). Those cases were not included in the analysis for this paper because we wanted the sub-groups to show distinct levels of target language experience (i.e., distinct cases of EL1 vs. EL2), which was operationalized in light of language dominance at home. The finding that the EL1 children had significantly higher English oral vocabulary (see Table 1) perhaps confirms the validity of this way of grouping, although it might be desirable in future research to use a better method and possibly generate a quantitative index for more refined grouping.

5. A reviewer asked that more information be provided on English language and literacy instruction, and the instruction in the MT or the EL2 children's primary languages (i.e., Chinese and Malay). It is beyond the purpose and the scope of this paper to provide substantial details on 
English and MT curriculums and instruction in Singapore; and because of the unique and changing bilingual landscape in Singapore, bilingual education in the country is too complex to be presented and appreciated in any simple language. Nonetheless, we hope the information below could be useful to interested readers, who, for further details, may refer to the school syllabuses accessible on the website of the Singapore Ministry of Education (https://www.moe.gov.sg/education/syllabuses) and Silver and Bokhorst-Heng (2016).

It is a cornerstone of the educational system in Singapore that all students receive formal instruction in both English and their respective MT to be bilingual and biliterate. This journey starts from preschool, which is almost universally attended by children in Singapore. The goals of learning in preschool include developing basic oral communication (e.g., listening comprehension and oral presentational and conversational skills) and literacy skills concurrently in both English and MT. Goals of English literacy learning include, for example, lower- and upper-case letters, sight word recognition, and awareness of written language conventions (https://www.moe.gov.sg/education/preschool/learning-areas-and-learning-goals).

When children are about 6-7 years old, they go to primary school where the journey of concurrent English and MT learning continues. The primary school English curriculum, titled STELLAR (STrategies for English Language Learning And Reading), is characterized by a combination of the so-called L1 (e.g., shared book reading) and L2 (e.g., explicit grammar 
instruction) teaching principles and strategies to promote the development of not only strong linguistic knowledge and oral proficiency but also literacy skills (Curdt-Christiansen \& Silver, 2013; Pang, Lim, Choe, Peters, \& Chua, 2015). In particular, all children, disregarding linguistic background (e.g., whether they speak English or MT as a dominant home language), receive explicit instruction on basic skills (e.g., phonics and phonemic awareness) for developing word reading accuracy and fluency in early primary school years. While the learning of morphology, such as derivational affixation, is indicated in the English Language Syllabus (Ministry of Education, 2008), overall the attention is limited in the curriculum and classroom instruction. MT education is broadly characterized by a similar approach, with attention to both oral communication (e.g., Mandarin for Chinese MT) and literacy skills (e.g., Chinese character recognition and writing), although the instructional time (4-6 hours a week, depending on grade levels) is much less than for English. In response to the gradual home language shift from MT to English and the changing linguistic landscape in the society in general, the Ministry of Education regularly reviews and modifies MT curriculums to accommodate the diverse needs in children from different home language backgrounds, particularly those from English-dominant families (Ministry of Education, 2011). A notable example is the modular, curricular approach for Chinese (Li, Zhao, \& Yeung, 2011; Ministry of Education, 2014a), which divides the Chinese language curriculum into a Core Module that everyone studies (about 70-80\% of the curriculum) 
and an adaptive module (20-30\%). Those who have low proficiency in Chinese, reasonably those from English-dominant families, are expected to study a bridging or consolidation module before they study the core module. Another example is the so-called "bilingual approach," which has underpinnings in using English to facilitate children's MT learning and has been recently advocated by some local scholars (e.g., Goh, 2018).

6. Given the alphabetic nature of Malay Rumi, it was not a surprise that the Malay EL2 group's phonemic decoding was significantly better than that of the Chinese EL2 group. But, why was no similar significant difference found of morphological decoding fluency between the two groups? We speculate that this might be because the derivational word decoding task consisted of real words and the stronger oral vocabulary knowledge of the Chinese EL2 group (see Table 1) might have compensated for their weaker morpheme-based decoding compared to the Malay EL2 group. The reason why the Chinese EL2 group had a greater oral vocabulary than their Malay counterpart was unknown. It might be related to variation in home English language use (the fact that both EL2 groups used their respective ethnic language as the dominant home language does not mean no English was used at home) or a differential effect of school English learning.

7. To explore the pattern in the Malay EL1 group, and as a response to a reviewer's comment, bivariate correlations as those reported in Table 2 were calculated. The correlation of oral vocabulary with reading comprehension was significant $(r=.525, p=.030)$. Although the 
correlation of morphological decoding fluency $(r=.460 ; p=.063)$ was slightly greater than that of phonemic decoding $(r=.431 ; p=.085)$ with reading comprehension, neither was significant. 


\section{References}

Adlof, S., Catts, H., \& Little, T. (2006). Should the simple view of reading include a fluency component? Reading and Writing: An Interdisciplinary Journal, 19, 933-958. https://doi.org/10.1007/s11145-006-9024-z

August, D., \& Shanahan, T. (2006). Developing literacy in second-language learners: Report of the National Literacy Panel on language-minority children and youth. Mahwah, NJ: Lawrence Erlbaum Associates.

Beck, I. (1989). Reading today and tomorrow: Banners. New York: Holt, Rinehart \& Winston.

Bowers, P.N., Kirby, J.R., \& Deacon, S.H. (2010). The effects of morphological instruction on literacy skills: A systematic review of the literature. Review of Educational Research, 80, 144-179. https://doi.org/10.3102/0034654309359353

Cain, K., \& Barnes, M.A. (2017). Reading comprehension: What develops and when? In K. Cain, D.L.Compton, \& R.K. Parrila (Eds.), Theories of reading development (pp. 257282). Amsterdam: John Benjamins Publishing. https://doi.org/10.1075/swll.15.15cai

Carlisle, J.F. (2003). Morphology matters in learning to read: A commentary. Reading Psychology, 24, 291-322. https://doi.org/10.1080/02702710390227369 
Carlisle, J.F., \& Fleming, J. (2003). Lexical processing of morphologically complex words in the elementary years. Scientific Studies of Reading, 7, 239-253.

https://doi.org/10.1207/S1532799XSSR0703_3

Catts, H.W. (2018). The Simple View of Reading: Advancements and false impressions. Remedial and Special Education, 39, 317-323.

https://doi.org/10.1177/0741932518767563

Chen, R., \& Vellutino, F.R. (1997). Prediction of reading ability: A cross-validation study of the simple view of reading. Journal of Literacy Research, 29, 1-24. https://doi.org/10.1080/10862969709547947

Chen, X., Ramirez, G., Luo, Y.C., Geva, E., \& Ku, Y.-M. (2012). Comparing vocabulary development in Spanish- and Chinese-speaking ELLs: The effects of metalinguistic and sociocultural factors. Reading and Writing: An Interdisciplinary Journal, 25, 1991-2020. https://doi.org/10.1007/s11145-011-9318-7

Clahsen, H., Felser, C., Neubauer, K., Sato, M., \& Silva, R. (2010). Morphological structure in native and nonnative language processing. Language Learning, 60, 21-43. https://doi.org/10.1111/j.1467-9922.2009.00550.x 
Coltheart, M. (2005). Modeling reading: The dual-route approach. In M.J. Snowling, \& C. Hulme (Eds.), The science of reading (pp. 6-23). Oxford, UK: Blackwell Publishing. https://doi.org/10.1002/9780470757642.ch1

Curdt-Christiansen, X.L., \& Silver, R. (2013). New wine into old skins: The enactment of literacy policy in Singapore. Language and Education, 27, 246-260. http://doi.org/10.1080/09500782.2012.704046

Curran, P.J., West, S.G., \& Finch, J.F. (1996). The robustness of test statistics to nonnormality and specification error in confirmatory factor analysis. Psychological Methods, 1, 16-29. https://doi.org/10.1037/1082-989X.1.1.16

Deacon, S.H., Francis, K, \& Tong, X. (2017). The relationship of morphological analysis and morphological decoding to reading comprehension. Journal of Research in Reading, 40, 1-16. https://doi.org/10.1111/1467-9817.12056

Deacon, S.H., \& Kieffer, M. (2018). Understanding how syntactic awareness contributes to reading comprehension: Evidence from mediation and longitudinal models. Journal of Educational Psychology, 110, 72-86. https://doi.org/10.1037/edu0000198

Dixon, L.Q. (2005). Bilingual education policy in Singapore: An analysis of its sociohistorical roots and current academic outcomes. International Journal of Bilingual Education and Bilingualism, 8, 25-47. https://doi.org/10.1080/jBEB.v8.i1.pg25 
Dunn, L.M., \& Dunn, D.M. (2007). Peabody Picture Vocabulary Test (4th ed.). Bloomington, MN: Pearson Assessments.

Florit, E., \& Cain, K. (2011). The Simple View of Reading: Is it valid for different types of alphabetic orthographies? Educational Psychology Review, 23, 553-576. https://doi.org/10.1007/s10648-011-9175-6

García, J.R., \& Cain, K. (2014). Decoding and reading comprehension: A meta-analysis to identify which reader and assessment characteristics influence the strength of the relationship in English. Review of Educational Research, 84, 74-111. https://doi.org/10.3102/0034654313499616

García, O. (2008). Bilingual education in the 21st Century: A global perspective. Malden, MA: Wiley-Blackwell.

Geva, E., \& Farnia, F. (2012). Developmental changes in the nature of language proficiency and reading fluency paint a more complex view of reading comprehension in ELL and EL1. Reading and Writing: An Interdisciplinary Journal, 25, 1819-1845. https://doi.org/10.1007/s11145-011-9333-8

Goh, Y.-S. (2018). Teaching Chinese as an International Language: A Singapore perspective. Cambridge: Cambridge University Press. https://doi.org/10.1017/9781107280472 
Goodwin, A.P., Gilbert, J.K., \& Choi, S.-J. (2013). Morphological contributions to adolescent word reading: An item response approach. Reading Research Quarterly, 48, 39-60. https://doi.org/10.1002/rrq.037

Goodwin, A.P., Huggins, A.C., Carlo, M.S., August, D., \& Calderon, M. (2013). Minding morphology: How morphological awareness relates to reading for English Language Learners. Reading and Writing: An Interdisciplinary Journal, 26, 1387-1415. https://doi.org/10.1007/s11145-012-9412-5

Gough, P.B., \& Tunmer, W.E. (1986). Decoding, reading and reading disability. Remedial and Special Education, 7, 6-10. https://doi.org/10.1177/074193258600700104

Hamada, M., \& Koda, K. (2008). Influence of first language orthographic experience on second language decoding and word learning. Language Learning, 58, 1-31. https://doi.org/10.1111/j.1467-9922.2007.00433.x

Hernández, A.C., Montelongo, J.A., \& Herter, R.J. (2016). Using Spanish-English cognates in children's choices picture books to develop Latino English learners' linguistic knowledge. The Reading Teacher, 70, 233-239. https://doi.org/10.1002/trtr.1511

Hoover, W.A., \& Gough, P.B. (1990). The simple view of reading. Reading and Writing: An Interdisciplinary Journal, 2, 127-160. https://doi.org/10.1007/BF00401799 
Hu, L.-Z., \& Bentler, P.M. (1999). Cutoff criteria for fit indexes in covariance structure analysis: Conventional criteria versus new alternatives. Structural Equation Modeling, 6, 1-55. https://doi.org/10.1080/10705519909540118

Johnston, T.C., \& Kirby, J.R. (2006). The contribution of naming speed to the simple view of reading. Reading and Writing: An Interdisciplinary Journal, 19, 339-361.

https://doi.org/10.1007/s11145-005-4644-2

Joshi, R.M., \& Aaron, P.G. (2000). The component model of reading: Simple view of reading made a little more complex. Reading Psychology, 21, 85-97. https://doi.org/10.1080/02702710050084428

Katz, L., \& Frost, R. (1992). The reading process is different for different orthographies: The orthographic depth hypothesis. In R. Frost \& L. Katz (Eds.), Advances in psychology, Vol. 94. Orthography, phonology, morphology, and meaning (pp. 67-84). Oxford, England: North-Holland. https://doi.org/10.1016/S0166-4115(08)62789-2

Kieffer, M.J., \& Lesaux, N.K. (2012). Direct and indirect roles of morphological awareness in the English reading comprehension of native English, Spanish, Filipino, and Vietnamese speakers. Language Learning, 62, 1170-1204. https://doi.org/10.1111/j.14679922.2012.00722.x 
Kim, Y.-S.G. (2017). Why the simple view of reading is not simplistic: Unpacking the simple view of reading using a direct and indirect effect model of reading (DIER). Scientific Studies of Reading, 21, 310-333. https://doi.org/10.1080/10888438.2017.1291643

Kirby, J.R. \& Bowers, P.N. (2017). Morphological instruction and literacy: Binding phonological, orthographic, and semantic features of words. In K. Cain, D.L. Compton, \& R.K. Parrila (Eds.), Theories of reading development (pp. 437-462). Amsterdam: John Benjamins Publishing. https://doi.org/0.1075/swll.15.24kir

Kirby, J.R., \& Savage, R. (2008). Can the simple view deal with the complexities of reading? Literacy, 42, 75-82. https://doi.org/10.1111/j.1741-4369.2008.00487.x

Koda, K. (2000). Cross-linguistic variations in L2 morphological awareness. Applied Psycholinguistics, 21, 297-320. https://doi.org/10.1017/S0142716400003015

Koda, K. (2007). Reading and language learning: Crosslinguistic constraints on second language reading development. Language Learning, 57(suppl 1), 1-44. https://doi.org/10.1111/j.1467-9922.2007.00411.x

Koda, K. (2008). Impacts of prior literacy experience on learning to read in a second language. In K. Koda \& A.M. Zehler (Eds.), Learning to read across languages: Cross-linguistic relationships in first- and second-language literacy development (pp. 68-96). New York: Routledge. 
Koda, K., Lü, C., \& Zhang, D. (2014). L1-induced facilitation in biliteracy development in

Chinese and English. In X. Chen, Q. Wang, \& Y.C. Luo (Eds.), Reading development and difficulties in monolingual and bilingual Chinese children (pp. 141-169). New York: Springer. https://doi.org/10.1007/978-94-007-7380-6_8

Lam, K., Chen, X., \& Deacon, S.H. (in press). The role of awareness of cross-language suffix correspondences in second-language reading comprehension. Reading Research Quarterly. https://doi.org/10.1002/rrq.257

Lam, K., Chen, X., Geva, E., Luo, Y.L., \& Li, H. (2012). The role of morphological awareness in reading achievement among young Chinese-speaking English language learners: A longitudinal study. Reading and Writing: An Interdisciplinary Journal, 25, 1847-1872. https://doi.org/10.1007/s11145-011-9329-4

Lesaux, N.K., Crosson, A.C., Kieffer, M.J., \& Pierce, M. (2010). Uneven profiles: Language minority learners' word reading, vocabulary, and reading comprehension skills. Journal of Applied Developmental Psychology, 31, 475-483.

https://doi.org/10.1016/j.appdev.2010.09.004

Lesaux, N.K., \& Siegel, L.S. (2003). The development of reading in children who speak English as a Second Language. Developmental Psychology, 39, 1005-1019.

https://doi.org/10.1037/0012-1649.39.6.1005 
Li. C., \& Thompson, S. (1981). Mandarin Chinese: A functional reference grammar. Berkeley, CA: University of California Press.

Li, L., Zhao, S., \& Yeung, A.S. (2012). Chinese language reform in Singapore: Teacher perceptions of instructional approaches and curriculum implementation. International Journal of Bilingual Education and Bilingualism, 15, 533-548.

https://doi.org/10.1080/13670050.2011.641938

Mahony, D., Singson, M., \& Mann, V. (2000). Reading ability and sensitivity to morphological relations. Reading and Writing: An Interdisciplinary Journal, 12, 191--218. https://doi.org/10.1023/A:1008136012492

Ministry of Education. (2008). English Language Syllabus 2010. Singapore: Curriculum Planning and Development Division, Ministry of Education.

Ministry of Education. (2011). Nurturing active learners and proficiency users: Report of the 2010 Mother Tongue Languages Review Committee. Singapore: Ministry of Education. Ministry of Education. (2014a). 2015 Syllabus Chinese Language Primary. Singapore: Curriculum Planning and Development Division, Ministry of Education. Ministry of Education (2014b). Malay Language Teaching and Learning Syllabus Primary One to Six. Singapore: Curriculum Planning and Development Division, Ministry of Education. 
Muljani, D., Koda, K., \& Moates, D.R. (1998). The development of word recognition in a second language. Applied Psycholinguistics, 19, 99-113.

https://doi.org/10.1017/S0142716400010602

Muthén, L.K., \& Muthén, B.O. (1998-2015). Mplus user's guide (7th ed.). Los Angeles, CA: Muthén \& Muthén.

Nagy, W.E. (2007). Metalinguistic awareness and the vocabulary-comprehension connection. In R.K. Wagner, A.E. Muse, \& K.R. Tannenbaum (Eds.), Vocabulary acquisition: Implications for reading comprehension (pp. 52-77). New York: The Guilford Press.

Nagy, W.E., \& Anderson, R.C. (1984). How many words are there in printed school English? Reading Research Quarterly, 19, 304-330. https://doi.org/10.2307/747823

Nagy, W.E., Carlisle, J.F., \& Goodwin, A.P. (2013). Morphological knowledge and literacy acquisition. Journal of Learning Disabilities, 47, 3-12. https://doi.org/10.1177/0022219413509967

Nimon, K. (2010). Regression commonality analysis: Demonstration of an SPSS solution. Multiple Linear Regression Viewpoints, 36, 10-17.

Nunes, T., Bryant, P., \& Barros, R. (2012). The development of word recognition and its significance for comprehension and fluency. Journal of Educational Psychology, 104, 959-973. https://doi.org/http://10.1037/a0027412 
Ouellette, G.P. (2006). What's meaning got to do with it: The role of vocabulary in word reading and reading comprehension. Journal of Educational Psychology, 98, 554-566. https://doi.org/10.1037/0022-0663.98.3.554

Packard, J.L. (2000). The morphology of Chinese: A linguistic and cognitive approach. Cambridge: Cambridge University Press. https://doi.org/10.1017/CBO9780511486821

Pakir, A. (1992). Issues in second language curriculum development: Singapore, Malaysia, Brunei. Annual Review of Applied Linguistics, 13, 3-23. https://doi.org/10.1017/S0267190500002361

Pang, E.S., Lim, V., Choe, K.C., Peters, C., \& Chua, L.C. (2015). System scaling in Singapore: The STELLAR story. In C.-K., Looi \& L.W. Teh (Eds.), Scaling educational innovations (pp. 105-122). Singapore: Springer. https://doi.org/10.1007/978-981-287-537-2_6

Paris, S. (2005). Reinterpreting the development of reading skills. Reading Research Quarterly, 40, 184-202. https://doi.org/10.1598/RRQ.40.2.3

Pasquarella, A., Chen, X., Gottardo, A., \& Geva, E. (2015). Cross-language transfer of word reading accuracy and word reading fluency in Spanish-English and Chinese-English bilinguals: Script-universal and script-specific processes. Journal of Educational Psychology, 107, 96-110. https://doi.org/10.1037/a0036966 
Pasquarella, A., Gottardo, A., \& Grant, A. (2012). Comparing factors related to reading comprehension in adolescents who speak English as a First (L1) or Second (L2) Language. Scientific Studies of Reading, 16, 474-503. https://doi.org/10.1080/10888438.2011.593066

Perfetti, C.A. (1985). Reading ability. New York: Oxford University Press.

Perfetti, C.A. (1999). Comprehending written language: A blueprint for the reader. In C. Brown \& P. Hagoort (Eds.), Neurocognition of language (pp. 167-208). Oxford: Oxford University Press. https://doi.org/10.1093/acprof:oso/9780198507932.003.0006

Perfetti, C.A. (2007). Reading ability: Lexical quality to comprehension. Scientific Studies of Reading, 11, 357-383. https://doi.org/10.1080/10888430701530730

Proctor, C.P., Carlo, M., August, D., \& Snow, C. (2005). Native Spanish-speaking children reading in English: Toward a model of comprehension. Journal of Educational Psychology, 97, 246-256. https://doi.org/10.1037/0022-0663.97.2.246

Ramirez, G., Chen, X., Geva, E., \& Kiefer, H. (2010). Morphological awareness in Spanishspeaking English language learners: Within and cross-language effects on word reading. Reading and Writing: An Interdisciplinary Journal, 23, 337-358. http://doi.org/10.1007/s11145-009-9203-9 
Ramirez, G., Chen, X., Geva, E., \& Luo, Y. (2011). Morphological awareness and word reading in English Language Learners: Evidence from Spanish- and Chinese-speaking children. Applied Psycholinguistics, 32, 601-618. https://doi.org/10.1017/S0142716411000233

Raven, J., Raven, J.C., \& Court, J.H. (1998). Manual for Raven's Progressive Matrices and Vocabulary Scales. Section 3, The Standard Progressive Matrices. Oxford: Oxford Psychologists Press/San Antonio, TX: The Psychological Corporation.

Richards, J.C., \& Schmidt, R. (2002). Longman dictionary of language teaching and applied linguistics. London: Pearson Education.

Rickard Liow, S.J., \& Lee, L.C. (2004). Metalinguistic awareness and semi-syllabic scripts: Children's spelling errors in Malay. Reading and Writing: An Interdisciplinary Journal, 17, 7-26. https://doi.org/10.1023/B:READ.0000013833.79570.de

Savage, R. (2006). Reading comprehension is not always the product of nonsense word decoding and linguistic comprehension: Evidence from teenagers who are extremely poor readers. Scientific Studies of Reading, 10, 143-164. https://doi.org/10.1207/s1532799xssr1002_2

Scarborough, H.S. (2001). Connecting early language and literacy to later reading (dis)abilities:

Evidence, theory, and practice. In S. Neuman \& D. Dickinson (Eds.), Handbook for research in early literacy (pp. 97-110). New York, NY: Guilford Press. 
Silver, R.E., \& Bokhorst-Heng, W.D. (Eds.). (2016). Quadrilingual education in Singapore:

Pedagogical innovation in language education. Singapore: Springer.

Silverman, R.D., Speece, D.L., Harring, J.R., \& Ritchey, K.D. (2013). Fluency has a role in the Simple View of Reading. Scientific Studies of Reading, 17, 108-133.

https://doi.org/10.1080/10888438.2011.618153

Tadmor, U. (2009). Malay-Indonesian. In B. Comrie (Ed.), The world's major languages (2nd ed.) (pp. 791-818). London: Routledge.

Tilstra, J., McMaster, K., Van Den Broek, P., Kendeou, P., \& Rapp, D. (2009). Simple but complex: Components of the simple view of reading across grade levels. Journal of Research in Reading, 32, 383-401. https://doi.org/10.1111/j.1467-9817.2009.01401.x

Torgesen, J.K., Wagner, R.K., \& Rashotte, C.A. (1999). Test of Word Reading Efficiency (TOWRE). Austin, TX: PRO-ED.

Tunmer, W.E., \& Chapman, J.W. (2012). The Simple View of Reading redux: Vocabulary knowledge and the independent components hypothesis. Journal of Learning Disabilities, 45, 453-466. https://doi.org/10.1177/0022219411432685

Tyler, A., \& Nagy, W. (1989). The acquisition of English derivational morphology. Journal of Memory and Language, 28, 649-667. https://doi.org/10.1016/0749-596X(89)90002-8 
Vellutino, F.R., Tunmer, W.E., Jaccard, J.J., \& Chen, R. (2007). Components of reading ability:

Multivariate evidence for a convergent skills model of reading development. Scientific

Studies of Reading, 11, 3-32. https://doi.org/10.1080/10888430709336632

Wang, M., Cheng, C. \& Chen, S.-W. (2006). Contribution of morphological awareness to Chinese-English biliteracy acquisition. Journal of Educational Psychology, 98, 542-553. http://doi.org/10.1037/0022-0663.98.3.542

Wang, M., \& Koda, K. (2005). Commonalities and differences in word identification skills among learners of English as a Second Language. Language Learning, 55, 71-98. http://doi.org/10.1111/j.1467-9922.2007.00416.x

Woodcock, R.W. (1998). Woodcock Reading Mastery Tests-Revised / Normative Update. Circle Pines, MN: American Guidance Service.

Yeong, S.H.M., \& Rickard Liow, S.J. (2012). Development of phonological awareness in English-Mandarin bilinguals: A comparison of English-L1 and Mandarin-L1 kindergarten children. Journal of Experimental Child Psychology, 112, 111-126. https://doi.org/10.1016/j.jecp.2011.12.006

Zhang, D. (2017). Word reading in L1 and L2 learners of Chinese: Similarities and differences in the functioning of component processes. Modern Language Journal, 101, 391-411. http://doi.org/10.1111/modl.12392 
Zhang, D., Koda, K., Leong, C.K., \& Pang, E. (2019). Cross-lagged analysis of reciprocal effects of morphological awareness and reading in Chinese in a multilingual context. Journal of Research in Reading, 42, 58-79. http://doi.org/10.1111/1467-9817.12135

Ziegler, J.C., \& Goswami, U. (2005). Reading acquisition, developmental dyslexia, and skilled reading across languages: A Psycholinguistic Grain Size theory. Psychological Bulletin, 131, 3-29. http://doi.org/10.1037/0033-2909.131.1.3 
DONGBO ZHANG (corresponding author) is a professor of language education in the Graduate

School of Education, University of Exeter, Exeter, Devon, United Kingdom; email

d.zhang4@exeter.ac.uk. His research interests include vocabulary and reading development in second language or bilingual learners.

SIHUI KE is an assistant professor in the Department of Modern \& Classical Languages, Literatures \& Cultures, University of Kentucky, Lexington, USA; email Sihui.Ke@uky.edu. Her research focuses on how adults and children develop reading competence in a second language. 


\section{Appendix}

\section{Morphological Decoding Fluency Task}

\section{Practice Items}

\begin{tabular}{|l|l|l|l|l|l|l|l|l|l|}
\hline 1. & beautiful & 2. & farmer & 3. & suitable & 4. & education & 5. & foolish \\
\hline 6. & exactly & 7. & leader & 8. & useful & 9. & famous & 10. & certainly \\
\hline
\end{tabular}

\section{Test Items}

\begin{tabular}{|l|l|l|l|l|l|l|l|l|l|}
\hline 1. & usually & 2. & various & 3. & discussion & 4. & natural & 5. & dangerous \\
\hline 6. & magician & 7. & agreement & 8. & easily & 9. & noisy & 10. & winner \\
\hline 11. & growth & 12. & decision & 13. & expression & 14. & acceptable & 15. & rainy \\
\hline 16. & similarity & 17. & emphasize & 18. & expensive & 19. & universal & 20. & intensity \\
\hline 21. & successful & 22. & quickly & 23. & economic & 24. & electricity & 25. & reporter \\
\hline 26. & productive & 27. & careless & 28. & sunny & 29. & dramatic & 30. & curiosity \\
\hline 31. & scientist & 32. & equality & 33. & happiness & 34. & historian & 35. & spacious \\
\hline 36. & majority & 37. & consideration & 38. & reality & 39. & lovable & 40. & dependence \\
\hline 41. & cultural & 42. & believable & 43. & peaceful & 44. & strength & 45. & humanity \\
\hline 46. & periodic & 47. & metallic & 48. & prevention & 49. & musician & 50. & supportive \\
\hline 51. & specialize & 52. & simply & 53. & kindness & 54. & length & 55. & partial \\
\hline 56. & continuous & 57. & introduction & 58. & runner & 59. & mysterious & 60. & possibly \\
\hline
\end{tabular}


Table 1.

Means and Standard Deviations of Performance on Tasks in Different Groups

\begin{tabular}{|c|c|c|c|c|c|c|c|c|c|}
\hline & \multicolumn{3}{|c|}{$\begin{array}{l}\text { Chinese EL1 } \\
\qquad(N=74)\end{array}$} & \multicolumn{3}{|c|}{$\begin{array}{l}\text { Chinese EL2 } \\
(N=105)\end{array}$} & \multicolumn{3}{|c|}{$\begin{array}{l}\text { Malay EL2 } \\
(N=60)\end{array}$} \\
\hline & $M(S D)$ & $S$ & $K$ & $M(S D)$ & $S$ & $K$ & $M(S D)$ & $S$ & $K$ \\
\hline $\begin{array}{l}\text { Nonverbal } \\
\text { Intelligence }\end{array}$ & $29.09(4.59)$ & -1.868 & 2.823 & $28.57(4.06)$ & -1.253 & 2.519 & $26.88(6.50)$ & -1.029 & .045 \\
\hline $\begin{array}{l}\text { Phonemic } \\
\text { Decoding }\end{array}$ & $31.27(3.80)$ & -.954 & .658 & $26.28(6.93)$ & -1.194 & 1.327 & $28.98(4.65)$ & -2.180 & 2.231 \\
\hline $\begin{array}{l}\text { Morphological } \\
\text { Decoding Fluency }\end{array}$ & $31.73(8.32)$ & -.053 & .643 & $24.70(10.49)$ & -.015 & .457 & $26.88(6.51)$ & -.076 & 2.586 \\
\hline Oral Vocabulary & $52.01(5.50)$ & -.918 & .222 & $45.19(8.97)$ & -.789 & .141 & $41.93(10.01)$ & -.509 & -.094 \\
\hline $\begin{array}{l}\text { Reading } \\
\text { Comprehension }\end{array}$ & $7.41(2.41)$ & -.428 & -.428 & $6.16(2.71)$ & .617 & -.325 & $5.27(2.95)$ & .584 & .569 \\
\hline
\end{tabular}

Note. EL1 = English as the dominant home language; EL2 = ethnic language as the dominant home language; $\mathrm{S}=\mathrm{Skewness} ; \mathrm{K}=$ Kurtosis. 
Table 2.

Intercorrelations between Literacy Variables

\begin{tabular}{|c|c|c|c|c|c|c|}
\hline & & 1 & 2 & 3 & 4 & 5 \\
\hline \multicolumn{7}{|c|}{ Chinese EL1 $(N=74)$} \\
\hline 1 & Nonverbal Intelligence & - & & & & \\
\hline 2 & Phonemic Decoding & .177 & - & & & \\
\hline 3 & Morphological Decoding Fluency & $.269 *$ & $.644 * * *$ & - & & \\
\hline 4 & Oral Vocabulary & $.256^{*}$ & $.599 * * *$ & $.523 * * *$ & - & \\
\hline 5 & Reading Comprehension & $.308 * *$ & $.486^{* * *}$ & $.668 * * *$ & $.560 * * *$ & - \\
\hline \multicolumn{7}{|c|}{ Chinese EL2 $(N=105)$} \\
\hline 1 & Nonverbal Intelligence & - & & & & \\
\hline 2 & Phonemic Decoding & $.209 *$ & - & & & \\
\hline 3 & Morphological Decoding Fluency & $.272 * *$ & $.827 * * *$ & - & & \\
\hline 4 & Oral Vocabulary & $.248 *$ & $.689 * * *$ & $.621 * * *$ & - & \\
\hline 5 & Reading Comprehension & $.224 *$ & $.542 * * *$ & $.464 * * *$ & $.584 * * *$ & - \\
\hline \multicolumn{7}{|c|}{ Malay EL2 $(N=60)$} \\
\hline 1 & Nonverbal Intelligence & - & & & & \\
\hline 2 & Phonemic Decoding & $.298 *$ & - & & & \\
\hline 3 & Morphological Decoding Fluency & $.360 * *$ & $.665^{* * *}$ & - & & \\
\hline 4 & Oral Vocabulary & $.374^{* *}$ & $.495^{* * *}$ & $.560 * * *$ & - & \\
\hline 5 & Reading Comprehension & $.298^{*}$ & $.554 * * *$ & $.630 * * *$ & $.595 * * *$ & - \\
\hline
\end{tabular}

Note. EL1 = English as the dominant home language; EL2 = ethnic language as the dominant home language.

$* p<.05 \quad * * p<.01 \quad * * * p<.001$ 
Table 3.

Goodness-of-Fit Indexes of Path Models Predicting Reading Comprehension in Different Groups

\begin{tabular}{|c|c|c|c|c|c|c|c|}
\hline & $\chi^{2}(d f)$ & $p$ & $\chi^{2} / d f$ & CFI & RMSEA (CI) & SRMR & $R^{2}$ \\
\hline Chinese EL1 & $2.247(2)$ & .325 & 1.124 & 977 & $.041(.000 .238)$ & .035 & .511 \\
\hline Chinese EL2 & $3.182(2)$ & .204 & 1.591 & .995 & $.075(.000 .222)$ & .028 & .383 \\
\hline Malay EL2 & $2.462(2)$ & .292 & 1.231 & .995 & $.062(.000 .272)$ & .045 & .498 \\
\hline \multicolumn{8}{|c|}{ Chinese EL1, Chinese EL2, and Malay EL2 a } \\
\hline Baseline & $7.891(6)$ & .246 & 1.315 & .996 & $.063(.000 .168)$ & .035 & - \\
\hline Constrained & $19.570(8)$ & .012 & 2.446 & .974 & $.135(.059 .212)$ & .048 & - \\
\hline \multicolumn{8}{|c|}{ Chinese EL1 vs. Chinese EL2 } \\
\hline Baseline & $5.429(4)$ & .246 & 1.357 & .996 & $.063(.027 .182)$ & .031 & - \\
\hline Constrained & $15.890(5)$ & .007 & 3.178 & .970 & $.156(.074 .245)$ & .047 & - \\
\hline \multicolumn{8}{|c|}{ Chinese EL2 vs. Malay EL2 } \\
\hline Baseline & $5.644(4)$ & .227 & 1.411 & .995 & $.071(.000 .192)$ & .045 & - \\
\hline Constrained & $10.800(5)$ & .056 & 2.160 & .982 & $.119(.000 .217)$ & .039 & - \\
\hline
\end{tabular}

Note. $\mathrm{EL} 1=$ English as the dominant home language; EL2 = ethnic language as the dominant home language.

a This refers to the model comparison across the three groups. The constrained model was significantly deviant from the baseline model, $\Delta \chi^{2}(2)=11.679, p=.003$. The baseline model was thus retained, which suggests that the path coefficient from morphological decoding fluency to reading comprehension significantly differed in the three groups. 
Table 4.

Path Coefficients of Models Predicting Reading Comprehension in Different Groups

\begin{tabular}{|c|c|c|c|c|}
\hline & Predictors & $\beta$ & $p$ & Unique $R^{2}$ \\
\hline \multirow[t]{4}{*}{ Chinese EL1 } & Nonverbal Intelligence & .104 & .225 & .010 \\
\hline & Phonemic Decoding & .034 & .772 & .001 \\
\hline & Morphological Decoding Fluency & .516 & $<.001$ & .142 \\
\hline & Oral Vocabulary & .287 & .005 & .049 \\
\hline \multirow[t]{4}{*}{ Chinese EL2 } & Nonverbal Intelligence & .078 & .334 & .006 \\
\hline & Phonemic Decoding & .288 & .051 & .022 \\
\hline & Morphological Decoding Fluency & .036 & .793 & .000 \\
\hline & Oral Vocabulary & .389 & $<.001$ & .077 \\
\hline \multirow[t]{4}{*}{ Malay EL2 } & Nonverbal Intelligence & .007 & .946 & .000 \\
\hline & Phonemic Decoding & .171 & .169 & .016 \\
\hline & Morphological Decoding Fluency & .334 & .010 & .054 \\
\hline & Oral Vocabulary & .321 & .004 & .067 \\
\hline
\end{tabular}

Note. $\mathrm{EL} 1=$ English as the dominant home language; EL2 = ethnic language as the dominant home language. 
1a (Chinese EL1)

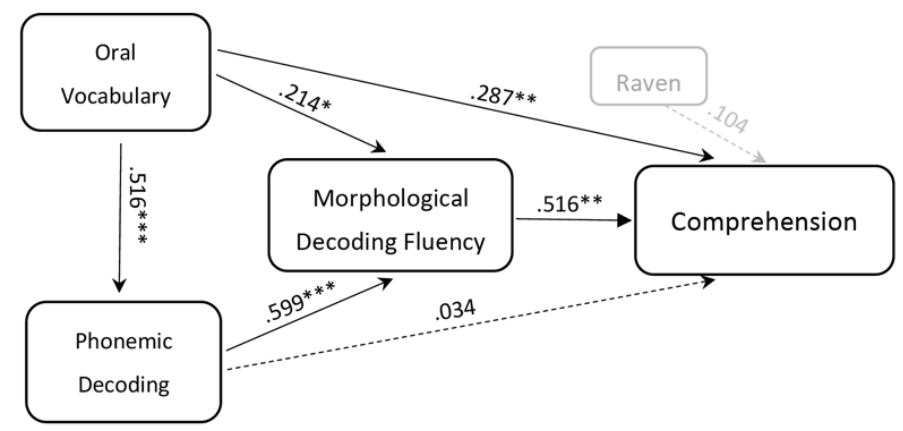

$1 b$ (Chinese EL2)

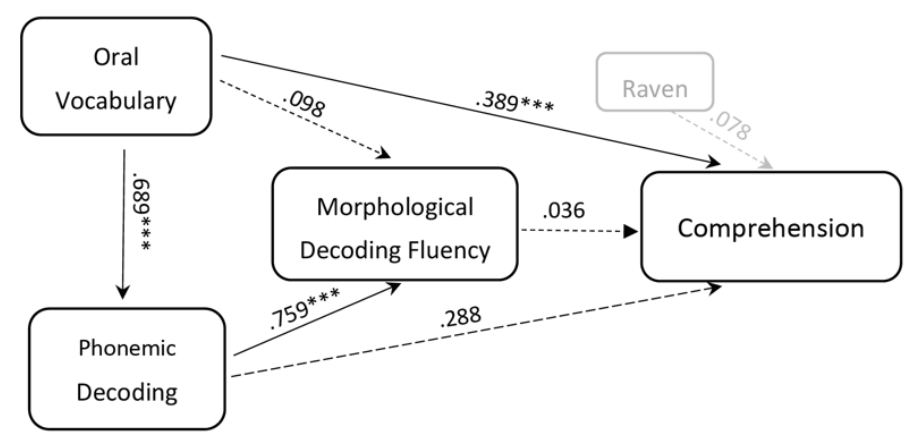

1c (Malay EL2)

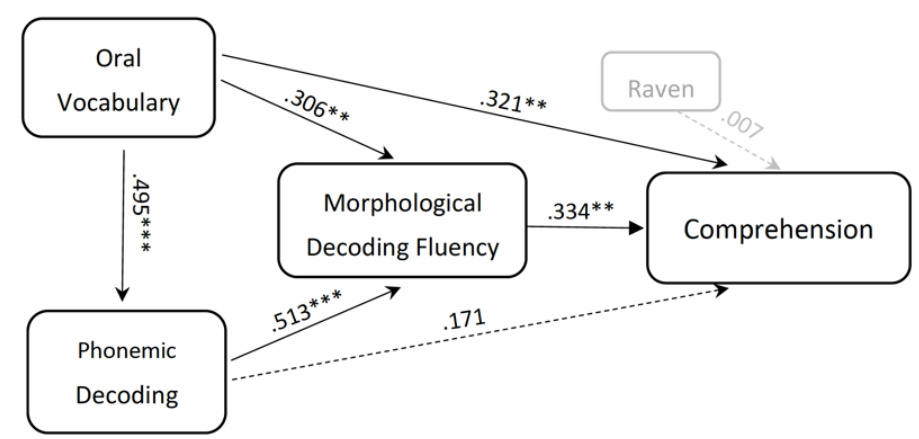

Figure 1. Path diagrams with standardized parameter estimates in the three groups.

Note. EL1 = English as the dominant home language; EL2 = ethnic language as the dominant home language.

$* p<.05 \quad * * p<.01 \quad * * * p<.001$ 